\title{
ANALISIS FAKTOR - FAKTOR YANG MEMPENGARUHI NIAT WAJIB WAJAK ORANG PRIBADI UNTUK MENYAMPAIKAN SURAT PEMBERITAHUAN SECARA ELEKTRONIK (E-FILLING)
}

\author{
Oleh: \\ Kartika' \\ Zainal Abidin \\ Dosen Fakultas Ekonomi Universitas Jember
}

\begin{abstract}
e-Filing is an innovation that is conducted by Directorate General of taxes to improve tax administration in Indonesia, a way of submitting Tax Return (TR) technology-based. Ease of submitting TR technology-based could improve taxpayer compliance in paying taxes, and it will have an impact to achieve realization target of tax revenue by Directorate General of taxes. Not only the technical aspects of developing and applying a technology, but also the social aspect is another aspect that accompany it, so it can not be separated from the other one. This research developed and modified a model of The Theory of Acceptance and Use of Technology (UTAUT) by adding some variable like personal characteristic and service quality.
\end{abstract}

Keywords: $\quad$ Performance Expectancy, Effort Expectancy, Social Influence, Trust in E-Filing Service Providers, Web SelfEfficacy, Perceived Security Control, Taxpayer Awareness, Service Quality, Intention to Use, UTAUT, E-Filing

\section{Pendahuluan}

Bersumber pada NK dan APBN 2016, 70\% lebih pendapatan negara bersumber dari penerimaan pajak. Peran pajak terhadap penerimaan negara diharapkan semakin meningkat setiap tahunnya terkait dengan tujuan pemerintah untuk meningkatkan kemandirian bangsa Indonesia dalam membiayai pembangunan dan pemerintahan melalui partisipasi aktif masyarakat berupa pajak.Menurut CITA (2016) untuk realisasi tahun 2015 merupakan realisasi yang terendah yaitu sebesar $81,5 \%$. Hal ini dikarenakan target pajak yang tidak realistis terlampau terlalu tinggi. Rasio kepatuhan pajak Indonesia masih rendah dibawah negara-negara lain. Pada tahun 2014 hanya 10,8 juta laporan SPT yang diterima dari 30,6 juta wajib pajak yang terdaftar (CITA, 2016). Struktur penerimaan pajak didominasi oleh oleh wajib pajak orang pribadi.

* Dosen Jurusan Akuntansi FE Unej

Dosen Program Studi Akuntansi Fakultas Ekonomi

Universitas Jember, Jember 
Kesuksesan administrasi perpajakan merupakan cerminan dari suksesnya penerimaan pajak, apabila pendekatan - pendekatan yang dilakukan untuk pengembangan administrasi perpajakan tidak sesuai maka akan dapat mengurangi beberapa aspek yang nantinya mempengaruhi penerimaan perpajakan (Camp, 2009). Salah satu inovasi dalam teknologi informasi di bidang perpajakan adalah dengan dikeluarkannya Peraturan Direktur Jenderal Pajak Nomor PER-03/PJ/2015 tentang Penyampaian Surat Pemberitahuan Elektronik oleh Direktur Jenderal Pajak pada tanggal 13 Februari 2015. Kesiapan e-Government di Indonesia menunjukkan posisi yang semakin menurun dari tahun ke tahun berbanding terbalik dengan jumlah pengguna internet yang meningkat secara signifikan (Rokhman, 2011).

Menurut Laudon dan Laudon (2007), sistem informasi merupakan sistem sosio teknikal, di dalamnya terdapat beberapa aspek yang terdiri dari mesin, perangkat dan teknologi fisik lainnya di mana mereka membutuhkan substansi sosial, organisasi dan investasi yang benar, agar sistem informasi dapat bekerja dengan baik. Oleh karena itu kegagalan penerapan sistem informasi saat ini tidak lagi dipandang dari aspek teknis, namun lebih kepada aspek perilaku.

Data wajib pajak untuk tahun pajak 2015 dari Kementrian Keuangan Republik Indonesia Sekretariat Jenderal Biro Komunikasi dan Layanan Informasi, data wajib pajak yang terdaftar sebanyak 30.044.103 Wajib Pajak untuk tahun pajak 2015. Dari jumlah Wajib Pajak yang terdaftar tesebut, hanya sebanyak 10.972.529 Wajib Pajak yang telah melaporkan SPT Tahunan baik manual maupun secara elektronik. Berdasarkan data tersebut menunjukkan bahwa masih sangat jauhnya implementasi $e$-Filing dibanding dengan jumlah data wajib pajak yang terdaftar di Direktorat Jenderal Pajak.

Sedangkan objek penelitian yang diteliti ialah wajib pajak di wilayah KPP Pratama Mojokerto dimana pengguna e-Filing terkait pelaporan SPT hanya berjumlah 48.429 dibandingkan dengan 153.999 jumlah wajib pajak yang wajib melaporkan SPT, selain itu terjadi penurunan pengguna $e$-Filing dari tahun sebelumnya turun sebesar 77,22\%. Beberapa masalah perpajakan lain yaitu terungkapnya KPP Pratama Mojokerto kehilangan penerimaan pajak sebesar 2,569 miliar rupiah pada tahun pajak 2015 dikarenakan wajib pajak tidak membayarkan tangunggan pajak (Hadi, 2015). Belum tercapainya target penerimaan pajak Direktorat Jenderal Pajak khususnya Direktorat Jenderal Pajak Kantor Wiayah Jawa Timur II yang baru tercapai 62\% (Hasan, 2015). (Astuti, 2015) dalam penelitiannya bahwa e-Filing mampu meningkatkan kepatuhan dengan kemudahan dalam penggunaannya, seperti mengurangi wajib pajak yang membayar lewat batas tempo serta mempercepat proses perekaman data wajib pajak. Menurut (Harinurdin, 2009) kepatuhan wajib pajak dan kesadaran wajib pajak merupakan faktor penting bagi peningkatan penerimaan perpajakan.

Sistem informasi merupakan seperangkat komponen yang saling berhubungan dan berfungsi untuk mengumpulkan, memproses,

Dosen Program Studi Akuntansi Fakultas Ekonomi 
menyimpan dan mendistribusikan informasi untuk mendukung pembuatan keputusan dan pengawasan dalam organisasi (Laudon dan Laudon, 2014). Pengertian Wajib Pajak menurut Pasal 1 Undang-Undang No.28 Tahun 2007 Tentang Perubahan Ketiga Atas Undang-Undang No. 6 Tahun 1983 Tentang Ketentuan Umum dan Tata Cara Perpajakan: "Wajib Pajak adalah orang pribadi atau badan, meliputi pembayar pajak, pemotong pajak, dan pemungut pajak, yang mempunyai hak dan kewajiban perpajakan sesuai dengan ketentuan peraturan perundang-undangan perpajakan". Definisi $e$ Filing menurut Peraturan Direktur Jenderal Pajak Nomor PER-26/PJ/2012 tentang Tata Cara Penerimaan dan Pengolahan Surat Pemberitahuan Tahunan adalah suatu cara penyampaian Surat Pemberitahuan (SPT) atau penyampaian Pemberitahuan Perpanjangan SPT Tahunan secara elektronik yang dilakukan secara online dan real time melalui website resmi DJP (efiling.pajak.go.id) atau Penyedia Jasa Aplikasi atau Application Service Provider (ASP).

Kegagalan sistem informasi pada beberapa dekade lalu cenderung berasal dari aspek teknisnya, yaitu pada buruknya kualitas teknis sistem teknologi informasi yang mengandung kesalahan-kesalahan sintak, kesalahan-kesalahan logik dan bahkan kesalahan-kesalahan informasi (Jogiyanto, 2007). Rokhman (2011) menyatakan bahwa ada beberapa kelemahan dalam model teori terdahulu terkait dengan penerimaan teknologi oleh pemakai sistem. Kelemahan-kelemahan pengujian model teori sebelumnya terletak pada penggunaan teknologi yang diteliti terlalu sederhana, partisipan mayoritas mahasiswa, waktu pengukuran yang tidak tepat, sifat pengukuran yang hanya cenderung menggunakan crosssectional, dan konteks pemakaian yang sempit (Jogiyanto, 2007). Beberapa alasan tersebut menjadi dasar pembentukan model baru oleh (Jogiyanto, 2007) yang dikenal dengan nama teori gabungan penerimaan dan penggunaan teknologi (Unified Theory of Acceptance and Use of Technology). Model ini dikembangkan dengan cara mengkaji dan menguji delapan model teori penerimaan teknologi terdahulu untuk menentukan variabel atau konstruk yang signifikan untuk digunakan di model gabungan baru . Model-model teori yang diuji terdiri dari Theory of Reasoned Action (TRA), Technology Acceptance Model (TAM), Motivational Model (MM), Theory of Planned Behavior (TPB), model gabungan TAM dan TPB, Model of PC Utilization (MPCU), Innovation Diffusion Theory (IDT), Sosial Cognitive Theory (SCT) (Jogiyanto, 2007).

Venkatesh et al. (2003) dalam (Jogiyanto, 2007) mendefinisikan ekspektasi kinerja sebagai tingkat kepercayaan individu terkait dengan penggunaan sistem akan membantu individu tersebut untuk mendapatkan keuntungan dalam performa kerjanya. Menurut Jogiyanto (2007), ekspektasi upaya adalah tingkat kemudahan yang dihubungkan dengan penggunaan suatu sistem.

Definisi faktor sosial menurut Thompson et al. (1991) adalah internalisasi individu tentang kultur subjektif grup acuan dan kesepakatan interpersonal spesifik yang dilakukan individu dengan orang lain di situasisituasi sosial spesifik. Jika pemerintah mampu menjaga kepercayaan

Dosen Program Studi Akuntansi Fakultas Ekonomi

Universitas Jember, Jember 
masyarakat atas sistem, maka penggunaan layanan pemerintah elektronik (e-Government) oleh masyarakat akan tinggi (Rehman et al., 2012). Penelitian Shaupp dan Carter (2010) menunjukkan adanya pengaruh antara tingkat kepercayaan dengan niat menggunakan e-Government.

Gambar 1

Kerangka Penelitian

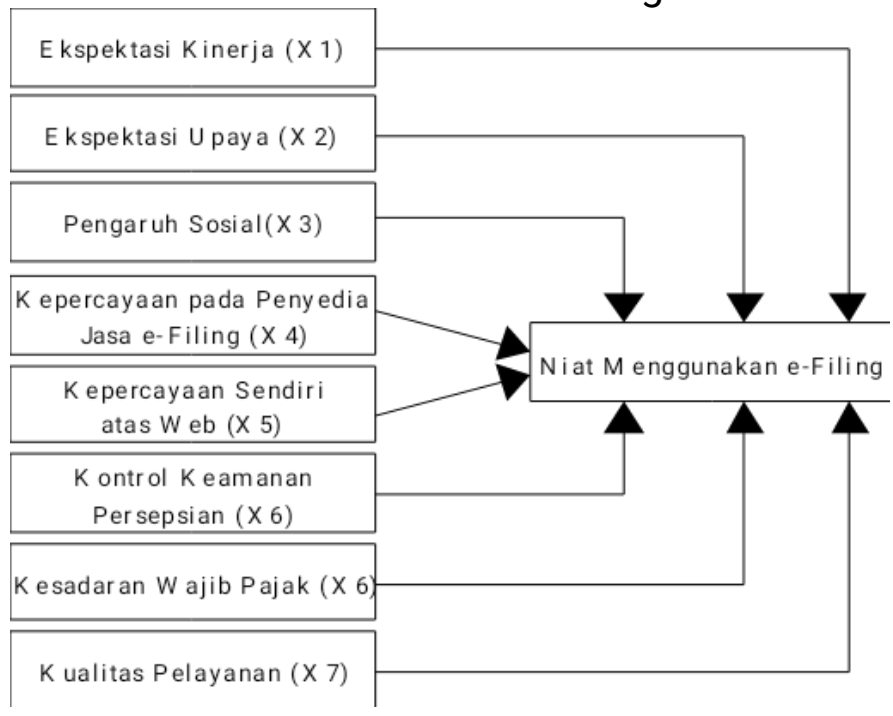

\section{Metode Penelitian}

\section{Jenis dan Sumber Data}

Jenis data yang digunakan dalam penelitian ini adalah jenis data subjek karena menggunakan kuesioner dalam memperoleh data dengan menggali opini, sikap dan pengalaman responden. Sedangkan sumber data yang digunakan adalah data primer dan sekunder, data primer diperoleh secara langsung dari responden melalui kuesioner tanpa melalui media perantara mengacu pada daftar pertanyaan yang sudah dipersiapkan (angket). Data sekunder sebagai pelengkap dan pendukung berupa bukti catatan dan literatur dari instansi yang terkait.

\section{Uji Kualitas Data}

Uji validitas dilakukan untuk mengetahui apakah alat ukur yang telah disusun memiliki validitas atau tidak, dan hasilnya ditunjukkan oleh suatu indeks yang menunjukkan seberapa jauh suatu alat ukur benar-benar mengukur apa yang perlu diukur. Uji reliabilitas dimaksudkan untuk 
mengetahui sejauh mana hasil pengukuran tetap konsisten, apabila dilakukan pengukuran dua kali atau lebih terhadap gejala yang sama dengan menggunakan alat ukur yang sama.

\section{Uji Asumsi Klasik}

Uji asumsi klasik meliputi normalitas, multikolinearitas, dan heteroskedastisitas. Uji multikolinearitas bertujuan untuk menguji apakah dalam model regresi ditemukan adanya korelasi antar variabel bebas. Selanjutnya heteroskedastisitas digunakan untuk menguji apakah dalam suatu model regresi terjadi ketidaksamaan variasi dari suatu residual suatu pengamatan ke pengamatan yang lain dengan varians yang berbeda. Sedangan uji normalitas digunakan untuk mengetahui apakah data terdistribusi normal atau tidak untuk menghindari terjadinya bias.

\section{Metode Analisis}

Metode analisis data yang digunakan pada penelitian ini adalah analisis statistik deskriptif untuk mengetahui pengaruh ekpektasi kinerja, ekspektasi usaha, pengaruh sosial, kepercayaan pada penyedia jasa $e^{-}$ Filing, keyakinan sendiri atas web, kontrol keamanan persepsian, kesadaran wajib pajak dan kualitas pelayanan terhadap niat wajib pajak untuk menggunakan e-Filing melalui analisis Regresi Linier Berganda. Dalam penelitian ini, unit analisis yang digunakan adalah wajib pajak orang pribadi pada Kantor Pelayanan Pajak Pratama Mojokerto.

\section{Hasil Penelitian \\ Analisis Regresi Linier Berganda}

Tabel 1

Hasil Analisis Regresi Linier Berganda

\begin{tabular}{|c|c|c|c|c|}
\hline \multirow[t]{2}{*}{ Variabel } & \multicolumn{2}{|c|}{$\begin{array}{l}\text { Unstandardized } \\
\text { Coeffecients }\end{array}$} & \multirow[b]{2}{*}{$\mathrm{T}$} & \multirow[t]{2}{*}{ Sig } \\
\hline & Beta & $\begin{array}{l}\text { Std. } \\
\text { Error }\end{array}$ & & \\
\hline C & $\begin{array}{r}1,07 \\
1\end{array}$ & 0,26 & 2,676 & 0,009 \\
\hline $\mathrm{X} 1$ & $\begin{array}{r}0,38 \\
6\end{array}$ & 0,158 & 2,453 & 0,016 \\
\hline $\mathrm{X} 2$ & $\begin{array}{r}0,21 \\
0\end{array}$ & 0,064 & 3,281 & 0,001 \\
\hline X3 & $\begin{array}{r}0,13 \\
0\end{array}$ & 0,081 & 1,600 & 0,113 \\
\hline$X 4$ & $\begin{array}{r}0,23 \\
8\end{array}$ & 0,077 & 3,079 & 0,003 \\
\hline
\end{tabular}




\begin{tabular}{rrrrr} 
X5 & 0,22 & 0,090 & 2,543 & 0,013 \\
$\times 6$ & 8 & & & \\
& 0,15 & 0,062 & 2,442 & 0,016 \\
$\times 7$ & 1 & & & \\
& 0,21 & 0,090 & 2,353 & 0,021 \\
X8 & 0,44 & 0,123 & 3,660 & 0,000 \\
& 9 & & & \\
\hline
\end{tabular}

Dari semua variabel independen ketujuh variabel mempunyai thitung diatas tabel, kecuali variabel $\mathrm{X} 4$ yaitu kepercayaan pada penyedia jasa $e^{-}$ Filing nilai thitung dbawah tabel, sedangkan tabel sendiri sebesar 1,660. Begitu juga yang terlihat pada nilai signifikansi ketujuh variabel berada dibawah 0,05, sedangkan untuk variabel $X 4$ yaitu kepercayaan pada penyedia jasa e-Filing dibawah 0,05.

Ekspektasi Kinerja berpengaruh terhadap Niat Menggunakan e-Filing dengan melihat taraf signifikansinya yaitu sebesar 0,016 . Hubungan yang ditunjukkan oleh koefisien regresi bernilai positif sebesar 0,386, artinya semakin baik Ekspektasi Kinerja maka Niat Menggunakan e-Filing semakin tinggi juga ( $\mathrm{H}_{1}$ diterima). Wajib pajak orang pribadi merasa terbantu untuk mengisi berbagai data yang ada di dalam SPT. Penyelesaian dalam penyampaian SPT yang semakin cepat dan mudah dirasa oleh wajib pajak mempengaruhi mereka untuk lebih cenderung menggunakan e-Filing.

Ekspektasi Upaya berpengaruh terhadap Niat Menggunakan e-Filing dengan melihat taraf signifikansinya yaitu sebesar 0,001 . Hubungan yang ditunjukkan oleh koefisien regresi bernilai positif sebesar 0,210, artinya semakin baik Ekspektasi Upaya maka Niat Menggunakan e-Filing semakin tinggi juga ( $\mathrm{H}_{2}$ diterima). Kemudahan e-Filing dalam menyajikan data-data SPT yang perlu diisi oleh wajib pajak orang pribadi, tidak perlu adanya banyak kertas yang dibutuhkan dan perubahan data yang mudah merupakan beberapa aspek yang memengaruhi wajib pajak orang pribadi untuk menggunakan e-Filing.

Pengaruh Sosial tidak berpengaruh terhadap Niat Menggunakan $e$ Filing dengan melihat taraf signifikansinya yaitu sebesar 0,113. Meskipun hubungan yang ditunjukkan oleh koefisien regresi bernilai positif sebesar 0,130 namun dilihat dari signifikansinya yang di atas 0,05, artinya Kepercayaan pada Penyedia Jasa e-Filing tidak berpengaruh terhadap Niat Menggunakan e-Filing $\left(\mathrm{H}_{3}\right.$ ditolak). Kenyataan di lapangan hasil penelitian, pengaruh eksternal di sekitar seseorang seperti keluarga, rekan dan wajib pajak lain sedikit mempengaruhi wajib pajak orang pribadi untuk menyapaikan SPT secara elektronik.

Kepercayaan pada Penyedia Jasa e-Filing berpengaruh terhadap Niat Menggunakan $e$-Filing dengan melihat taraf signifikansinya yaitu sebesar 0,003 . Hubungan yang ditunjukkan oleh koefisien regresi bernilai positif 
sebesar 0,238, artinya semakin baik Pengaruh Sosial maka Niat Menggunakan $e$-Filing semakin tinggi juga ( $\mathrm{H}_{4}$ diterima). Terdaftar secara resmi oleh DJP serta adanya ketentuan penggunaan dari pemerintah untuk menggunakan penyedia jasa e-Filing baik untuk pihak ketiga maupun dari DJP itu sendiri, merupakan beberapa hal yang dapat membuat wajib pajak percaya terhadap adanya penyedia jasa e-filing baik website resmi dari DJP itu sendiri ataupun website pihak ketiga lainnya.

Keyakinan-sendiri web berpengaruh terhadap Niat Menggunakan $e$ Filing dengan melihat taraf signifikansinya yaitu sebesar 0,013. Hubungan yang ditunjukkan oleh koefisien regresi bernilai positif sebesar 0,228, artinya semakin baik Keyakinan-sendiri web maka Niat Menggunakan e-Filing semakin tinggi juga ( $\mathrm{H}_{5}$ diterima). Banyaknya panduan, pelatihan dan tutorial penggunaan website e-Filing serta website yang dibuat user friendly memberikan kepercayaan-sendiri pada wajib pajak untuk mengoperasikan website e-Filing seperti memilih menu, memilih link atau tautan dan mengisi data-data pada suatu halaman di website e-Filing.

Kontrol Keamanan Persepsian berpengaruh terhadap Niat Menggunakan $e$-Filing dengan melihat taraf signifikansinya yaitu sebesar 0,016 . Hubungan yang ditunjukkan oleh koefisien regresi bernilai positif sebesar 0,151, artinya semakin baik Kontrol Keamanan Persepsian maka Niat Menggunakan e-Filing semakin tinggi juga $\left(\mathrm{H}_{6}\right.$ diterima). Beberapa hal terkait e-Filing mulai dari pendaftaran sampai dengan pelaporan sudah diatur sedemikian rupa dalam sebuah peraturan yang diterbitkan oleh DJP, setidaknya dapat meningkatkan persepsi keamanan pada wajib pajak itu sendiri.

Kesadaran Wajib Pajak berpengaruh terhadap Niat Menggunakan $e$ Filing dengan melihat taraf signifikansinya yaitu sebesar 0,021. Hubungan yang ditunjukkan oleh koefisien regresi bernilai positif sebesar 0,212, artinya semakin baik Kesadaran Wajib Pajak maka Niat Menggunakan e-Filing semakin tinggi juga $\left(\mathrm{H}_{7}\right.$ diterima). Keberadaan $e$ Filing pada lingkungan wajib pajak sudah ada sejak beberapa tahun yang lalu, kesadaran wajib pajak mulai tumbuh seiring dengan berkembangnya teknologi khususnya komputasi dan internet.

Kualitas Pelayanan berpengaruh terhadap Niat Menggunakan e-Filing dengan melihat taraf signifikansinya yaitu sebesar 0,000 . Hubungan yang ditunjukkan oleh koefisien regresi bernilai positif sebesar 0,449, artinya semakin baik Kualitas Pelayanan maka Niat Menggunakan e-Filing semakin tinggi juga $\left(\mathrm{H}_{8}\right.$ diterima). Berbagai kualitas pelayanan e-Filing yang ditawarkan oleh DJP memberikan pengaruh terhadap wajib pajak orang pribadi untuk menggunakan e-Filing.

Hasil analisis data dengan uji $\mathrm{F}$, menunjukkan bahwa adanya pengaruh yang signifikan dari ekpektasi kinerja, ekspektasi usaha, pengaruh sosial, kepercayaan pada penyedia jasa e-Filing, keyakinan sendiri atas web, kontrol keamanan persepsian, kesadaran wajib pajak dan kualitas pelayanan terhadap niat wajib pajak untuk menggunakan e-Filing di KPP

Dosen Program Studi Akuntansi Fakultas Ekonomi 
Pratama Mojokerto secara simultan atau bersama - sama, sesuai dengan nilai signifikansi 0,000 yang lebih kecil dari tingkat signifikasi 5\% dan nilai $F_{\text {hitung }}$ sebesar 4,910 berada diatas nilai $F_{\text {tabel }}$ sebesar 2,03 Hal ini didukung juga dengan nilai Adjusted $\mathrm{R}^{2}$ sebesar 0,240 dimana hubungannya cukup kuat dan searah, artinya apabila ada kenaikan pada variabel bebas yaitu ekpektasi kinerja, ekspektasi usaha, pengaruh sosial, kepercayaan pada penyedia jasa e-Filing, keyakinan sendiri atas web, kontrol keamanan persepsian, kesadaran wajib pajak dan kualitas pelayanan maka akan diikuti pula pada kenaikan variabel terikatnya yaitu niat wajib pajak untuk menggunakan e-Filing.

\section{Kesimpulan}

Hasil pengujian regresi sederhana atas pengaruh Ekspektasi Kinerja, Ekspektasi upaya, kepercayaan pada penyedia jasa, keyakinan akan diri sendiri, pengaruh control keamanan, kesadaran wajib pajak dan kualitas pelayanan terhadap Niat Menggunakan e-Filing menunjukkan hubungan yang positif signifikan. Sedangkan pengaruh Pengaruh Sosial terhadap Niat Menggunakan e-Filing menunjukkan nilai yang positif namun tidak signifikan. Ini membuktikan Pengaruh Sosial tidak berpengaruh terhadap Niat Menggunakan e-Filing

\section{Daftar Pustaka}

Astuti, Inne Nidya. (2015). Analisis Penerapan E-filing Sebagai Upaya Meningkatkan Kepatuhan Wajib Pajak dalam Penyampaian Surat Pemberitahuan (SPT) Tahunan pada Kantor Pelayanan Pajak Pratama Gresik Utara. Jurnal Akuntansi UNESA, Vol. 3, No. 3.

Camp, Bryan T. .(2009). Theory and Practice in Tax Administration. Virginia Tax Review, Vol. 29, 227-291.

Center for Indonesia Taxation Analysis (CITA). 2016. Keadilan Pajak dan Ketimpangan Pendapatan. [Diakses pada 4 Juni 2016]

http://www.cita.or.id/wp-content/uploads/2016/03/Keadilan-Pajak-dan-

Ketimpangan-Pendapatan-full-200px.jpg

Hadi, Nur. 2015. Tempo.co: Kantor Pajak Jawa Timur Sandera 3 Wajib Pajak di LP Porong. [Diakses pada 23 Agustus 2016]

https://m.tempo.co/amphtml/read/news/2015/10/09/092708044/kantorpajak-jawa-timur-sandera-3-wajib-pajak-di-lp-porong.

Hasan, Atiqoh. 2015. Pojokpitu.com: Sisa 2 Bulan, Setoran Pajak Kanwil DJP // Jatim Masih 62 Persen. [Diakses pada 23 Agustus 2016]

http://pojokpitu.com/baca.php?idurut=17921.

Jogiyanto, H. M. (2007). Sistem Informasi Keperilakuan. Penerbit Andi, Yogyakarta: Penerbit Andi.

Laudon, Kenneth C., \& Jane P. Laudon. (2014). Management Information Systems: Managing Digital Firm. England: Pearson Education Limited. Rehman, M., Esichaikul, V., \& Kamal, M. (2012). Factors influencing egovernment adoption in Pakistan. Transforming Government: People, Process and Policy, 6(3), 258-282.

Republik Indonesia, Peraturan Direktorat Jenderal Pajak Nomor PER-

Dosen Program Studi Akuntansi Fakultas Ekonomi

Universitas Jember, Jember 
03/PJ/2015 tentang Penyampaian Surat Pemberitahuan Elektronik.

Shaupp, L. C., \& Carter, L. (2010). The Impact of trust, risk and optimism bias on e-file adoption. Information System Frontiers, 12(3), 299-309.

Rokhman, A. (2011). E-Government Adoption in Developing Countries; the Case of Indonesia. Journal of Emerging Trends in Computing and Information Sciences, 2(5), 228-236.

Thompson, R. L., Higgins, C. A., \& Howell, J. M. (1991). Personal computing: Toward a conceptual model ofutilization. MIS quarterly, 125-143. 